\title{
Uma experiência de mudança da gestão universitária: o percurso ambivalente entre proposições e realizações*
}

\author{
Rosely Moraes Sampaio** \\ Ruthy Nadia Laniado***
}

\begin{abstract}
Sumário: 1. Introdução; 2. Considerações sobre o tema; 3 . O estudo do objeto de pesquisa; 4 . $O$ contexto das propostas de modernização; 5 . Implantação de um novo modelo de desenvolvimento gerencial da Uesb; 6. Orçamento participativo na Uesb: uma prática democrática; 7. A dinâmica de implantação dos projetos: entre o planejado e o realizado; 8. Considerações finais.

Summary: 1. Introduction; 2. Considerations about the topic; 3. The subject matter of the study; 4 . The context of the proposals for modernization; 5. Implementation of a new model of management development for Uesb; 6. Participatory budgeting in Uesb: a democratic practice; 7. The dynamics of the implementation of projects: between the plan and achievement; 8. Final remarks.
\end{abstract}

Palavras-chave: gestão administrativa; universidade; cultura; modernização.

KEY WORDS: management; university; culture; modernization.

Este artigo analisa uma experiência de mudança e modernização da gestão administrativa universitária, observando a relação entre iniciativas, proposições e efetivação

\footnotetext{
* Artigo recebido em jan. e aceito em nov. 2008.

** Mestre em administração pela Universidade Federal da Bahia (UFBA), especialista em gestão universitária e qualidade em serviços pela UFBA. Pertence ao quadro funcional da Universidade Estadual do Oeste da Bahia. Pesquisadora associada do Núcleo de Estudos sobre Poder e Organizações Locais (Nepol/UFBA). Endereço: Rua Maranhão, 420, ap. 110 - Pituba — CEP 41830-260, Salvador, Bahia, Brasil. E-mail: rosely@ufba.br.

$* * * \mathrm{PhD}$ em ciência política pela Universidade de Essex (Inglaterra), pesquisadora visitante da Universidade de Cambridge (Inglaterra). Professora associada da Universidade Federal da Bahia (UFBA) e pesquisadora do CNPq. Pesquisadora associada do Núcleo de Estudos sobre Poder e Organizações Locais (Nepol/UFBA) e do Laboratório de Análise Política Mundial (Labmundo/ UFBA). Endereço: Avenida Reitor Miguel Calmon, s/n - Canela - CEP 40110-903, Salvador, Bahia, Brasil. E-mail: ruthy@ufba.br.
} 
de projetos, considerando o padrão dos valores culturais que facilitam ou não um processo de mudança na gestão. Para tanto, pesquisou-se duas propostas de modernização para a Universidade Estadual do Sudoeste da Bahia, elaboradas entre 1999 e 2001. O estudo de caso se apoiou em análise documental e entrevistas com os gestores envolvidos nos projetos. A interpretação das informações obtidas revela que valores culturais e padrões de conduta dos atores influenciam de forma relevante as estruturas conservadoras organizacionais e viabilizam mudanças. O modo como os atores percebem o sentido da mudança e os valores arraigados determinam os limites e o nível de consecução de iniciativas modernizadoras da gestão.

An experience of change in higher education management: the ambivalent course between the proposition and achievement

This article analyzes the experience of change and modernization in higher education management by looking at the relation between initiatives, propositions and accomplishment of projects. This takes into account the standard of culture values which makes the process of change easy or not. As a result, two proposals prepared for the modernization of the State University of the Southwest of Bahia (Uesb) were researched between 1999 and 2001. The case study was based on the documental analysis and interviews with the manager engaged in the projects. The interpretation of information collected reveals that the culture values and standards of procedure of the actors influence relevantly the organizational and traditional structures and make the changes viable. The way how the actors perceive the meaning of change and the deep-rooted values establish the limits and the level of attainment of modern initiatives for management.

\section{Introdução}

Este artigo analisa uma experiência de mudança e modernização da gestão administrativa universitária, observando a relação entre iniciativas, proposições e efetivação de projetos, considerando o padrão dos valores culturais que facilitam ou não um processo de mudança na gestão. Toma-se como pressuposto que os projetos de mudança e modernização institucional envolvem: dificuldades que a universidade enfrenta; as novas abordagens sobre mudanças que permitem tornar a organização de ensino superior atualizada em seu tempo; e os impactos das propostas sobre a realidade vivida pela organização conforme o nível de amadurecimento das mesmas e a vontade dos indivíduos envolvidos em torná-las bem-sucedidas. No cerne dessas questões que envolvem fatores objetivos e subjetivos, considera-se que os padrões culturais de comportamento implicam, igualmente, condições fundamentais de realização de projetos de modernização, remetendo as características das iniciativas aos atributos do capital social (Putnam, 2000), como a cooperação e a partici- 
pação na consecução das propostas, além dos valores de cultura política que moldam as condutas.

Para tanto, foram pesquisados dois projetos de modernização para a Universidade Estadual do Sudoeste da Bahia, elaborados entre 1999 e 2001. O estudo de caso se apoiou em análise documental e entrevistas com os gestores envolvidos nos projetos; buscou entender o nível de consecução que eles alcançaram na Uesb em termos das diferentes etapas de concepção e discussão; e os esforços de implementação dos mesmos. O caráter impreciso dos textos das propostas, confirmado também pelas informações de caráter muito genérico obtidas nos depoimentos, mostra que as questões de ordem política na organização universitária pesam, consideravelmente, nas iniciativas e decisões que são essenciais para as suas atividades-fim e atividades-meio. A pesquisa identificou os limites que determinaram o alcance dos resultados de mudança e modernização; eles são analisados neste artigo em relação ao objeto de pesquisa - os dois projetos selecionados para estudo - , ao contexto das propostas de modernização, assim como em relação à dinâmica entre o planejado e o realizado. Empiricamente, os dados podem ser observados na análise das iniciativas propostas desde 1993, os quatro eixos de convergência identificados nos dois projetos de modernização em relação à ação administrativa, valores e instâncias decisórias, assim como os fatores de caráter institucional, político e sociocultural que, finalmente, limitaram a implantação dos projetos. Entende-se que o modo como os atores percebem o sentido da mudança, os valores arraigados e o nível de politização da gestão universitária determinam os limites e o grau de consecução de iniciativas modernizadoras de gestão em organizações dessa natureza.

\section{Considerações sobre o tema}

A modernização das universidades públicas brasileiras foi objeto central da reforma universitária em 1968 e, desde então, retorna constantemente entre as questões relativas à reforma do Estado e o debate sobre a reforma do sistema universitário brasileiro. No entanto, o momento atual apresenta diferenças substantivas daquele produzido na década de 1960. Para Santos (1999), a universidade, em particular a pública, defronta-se com a necessidade de romper com o atual modelo que a enrijece, mas sugere que são difíceis as condições para enfrentar esse desafio, que requer transformações profundas e não ações parcelares. Tal limite, mais do que conjuntural, parece ser estrutural na medida em que a longevidade da instituição universitária no Ocidente parece estar 
associada a uma rigidez funcional e organizacional que causa uma relativa impermeabilidade a pressões externas, até mesmo uma aversão a mudanças.

Santos (1999) discute os parâmetros da complexa situação em que se defronta a universidade hoje e aponta algumas das dificuldades para a própria definição de suas funções sociais. Por serem múltiplas, elas geram antagonismos de difícil compatibilização. Pela sua capacidade de inovar e pelas estratégias que assumem (ao mesmo tempo de ocultação e compatibilização dos antagonismos), as funções sociais da universidade formam os limites da capacidade de mudança da própria universidade e são, hoje, o tema central de uma abordagem sociológica e gerencial da instituição. Analisando criticamente o modelo atual, o autor afirma que é da natureza das instituições universitárias não intervir no nível das causas profundas de suas contradições, priorizando a gestão das tensões que tendem a se tornar sistêmicas e representam, sempre, a reprodução controlada de uma crise orgânica.

Trigueiro (1999) corrobora as críticas de Santos (1999). Desenvolve como argumento que a principal ameaça à universidade não está fora dela, mas em seu próprio interior: as práticas obsoletas, a dificuldade em adequarse a um novo contexto de relações sociais em um mundo economicamente complexo, caracterizando um conservadorismo persistente. Ademais, há os problemas do corporativismo e de um individualismo exacerbado. Pode-se dizer que, em última instância, esses fatores reduzem o potencial inovador e criativo dessas agências que, paradoxalmente, são parte do nervo central de transformação do mundo social por meio da educação, do conhecimento e da ciência.

Há ainda a questão que diz respeito à renovação dos modelos administrativos da gestão universitária, que articulam pólos opostos que se estendem desde as críticas ao extremo da burocratização, a fragmentação departamental na organização do trabalho e os mecanismos de participação e decisão colegiados, até a autonomia como princípio acadêmico-administrativo para melhorar a própria racionalidade administrativa, a eficiência na alocação dos recursos, na qualificação de pessoal etc. Catani e colaboradores (2000) sugerem que o interesse em estudos que tratem da organização e gestão acadêmicas se pautem na necessidade de modernização-modelação institucional requerida pelos gestores, no sentido de formular sistemas de informação (para um maior planejamento das atividades) associados a políticas que tornem mais ágeis e eficientes o trabalho. Além disso, indicam a importância de ações no âmbito de cada instituição, para tornar a gestão mais profissional e a estrutura acadêmica cada vez mais funcional. Ressaltam Catani e colaboradores (2001:72) que 
de algum modo, os compromissos dos diferentes segmentos acadêmicos organizados com a gestão democrática nas universidades públicas parecem ter se vinculado à formulação de um modo de produzir que fosse mais eficiente socialmente, mas que não eximia essas instituições de uma reorganização interna do trabalho acadêmico.

Os autores que se preocupam com a temática da modernização na universidade brasileira, e que são referência para este artigo, concordam que as questões relacionadas à gestão universitária quase sempre são adjetivadas com os atributos da racionalidade técnica calcados nos princípios isolados da eficiência e eficácia, aspectos particulares do modelo produtivista de mercado. Essa lógica de orientação insere, no debate, a função crítica da universidade em contribuir para a produção e reprodução de valores e conhecimentos, que se relacionam com o desenvolvimento da sociedade, com o fortalecimento das instituições e com o fomento da cidadania ativa. Esta última anuvia a importância da participação e da cultura política e cívica sobre direitos e deveres nos debates sobre o assunto. Contrariamente a uma visão produtivista, neste artigo consideramos que o compromisso social da universidade em produzir conhecimento permite um desenvolvimento com integração social por meio dos seus produtos e da formação de recursos humanos competentes para as constantes demandas que surgem. É possível supor que a universidade é parte de uma sociedade civil capaz de garantir a liberdade, a igualdade, a justiça e as oportunidades de uma boa vida, fomentando uma cultura política que incrementa o sentido do bem comum e a solidariedade, bases da democracia moderna e da cidadania na sociedade de classes. Pode-se acrescentar que a democracia e a boa condição de vida se beneficiam de uma universidade que se transforma e, reflexivamente, influencia a transformação da própria democracia de modo mais substantivo.

\section{0 estudo do objeto de pesquisa}

Para investigar o tema e aprofundar os aspectos importantes no âmbito da modernização da gestão, optou-se por um estudo de caso, para diagnosticar as nervuras de uma situação institucional em relação às iniciativas e limites da modernização da gestão administrativa universitária: a Universidade Estadual do Sudoeste da Bahia (Uesb). A metodologia privilegiou a análise qualitativa em profundidade, o que permitiu revelar as múltiplas dimensões do contexto em termos de consenso, divergências e conflitos e descrever algumas situações em que o fato revela os próprios elementos que permitem direcionar a inves- 
tigação, às vezes não facilmente discerníveis nas proposições iniciais da pesquisa (Richardson, 1999; Godoy, 1995; Yin, 1990). Os dados que informam o estudo de caso foram organizados a partir da análise documental de dois projetos de modernização universitária da Uesb: projeto de implantação de um novo modelo de desenvolvimento gerencial na Uesb, de 1999; e orçamento participativo na Uesb - uma prática democrática, de 2001. O estudo desses projetos foi integrado a um programa de entrevistas abertas com os principais agentes institucionais envolvidos na produção e negociação dos mesmos. Os dados permitiram identificar por meio da sequência dos eventos a cadeia de (in)decisões, alianças ou (i)mobilização na elaboração e esforços de implementação dos referidos projetos. O tratamento dos dados foi de análise de conteúdo, com a categorização das informações abertas que acompanharam a dinâmica política do processo de decisão que envolveu os projetos.

\section{0 contexto das propostas de modernização}

A pauta de exigências imposta às universidades de grande porte possui similitude com as preocupações das universidades de médio e pequeno portes existentes no Brasil. Embora sejam de tamanho e complexidade diversas, os desafios enfrentados pelos gestores se assemelham, quer sejam decorrentes da estrutura organizacional, das modalidades de gestão ou das políticas de ensino superior adotadas. Este pressuposto é válido para a Uesb, uma entidade pública estadual baiana de médio porte e com caráter regional.

Os gestores eleitos para o período 1999-2003 propuseram os projetos já mencionados, visando tanto às novas práticas de administração e gestão como responder à necessidade da própria modernização institucional em um contexto de mudanças nas políticas públicas e do Estado. Mas o foco político das propostas enfatizou a importância da gestão participativa, que é reafirmada ao longo dos próprios depoimentos, repetindo experiências observadas em outras universidades brasileiras (Penteado, 1998). Há uma visão que acentua a demanda por modos organizacionais compartilhados capazes de conjugar a ação coletiva com a vontade dos envolvidos, os valores da participação e com os objetivos concretos da instituição.

O escopo temporal de modernização da Uesb foi mais amplo do que o período dos quatro anos que delimitaram os dois projetos. Havia uma consciência estabelecida há longo tempo sobre a importância da modernização dessa universidade. Foram várias iniciativas que, observadas de forma mais sistemática, possibilitaram traçar a dinâmica do esforço orientado para a modernização, marcando as preocupações sobre gestão e administração, recursos 
humanos e finanças. As principais iniciativas que foram identificadas pela pesquisa podem ser observadas no quadro 1 .

\section{Iniciativas de mudanças e modernização da Uesb (1993-99)}

\begin{tabular}{|c|c|c|}
\hline Ano & Plano/Atividade & Descrição \\
\hline 1993 & $\begin{array}{l}\text { Plano geral de } \\
\text { atividades }\end{array}$ & $\begin{array}{l}\text { Plano de açães para o ano de 1993, que define seis diretrizes: melhoria } \\
\text { da qualidade de ensino, reconhecimento da universidade na elaboração } \\
\text { de projetos para a criação de novos cursos, ampliação do espaço físico, } \\
\text { integração universidade versus comunidade, elaboração de uma política de } \\
\text { recursos humanos e modernização administrativa. }\end{array}$ \\
\hline 1993 & $\begin{array}{l}\text { Plano de } \\
\text { aplicação de } \\
\text { recursos - PAR }\end{array}$ & $\begin{array}{l}\text { Programa implantado em } 1993 \text { com a finalidade de acompanhar e dar } \\
\text { visibilidade aos gastos públicos realizados e servir de instrumento de } \\
\text { suporte para a tomada de decisão, melhorar a racionalização e distribuição } \\
\text { dos recursos financeiros. }\end{array}$ \\
\hline 1995 & $\begin{array}{l}\text { Programa de } \\
\text { gestão 1995-99 }\end{array}$ & $\begin{array}{l}\text { Plano elaborado com a participação das instâncias deliberativas e } \\
\text { representativas da comunidade universitária. Objetivos: propor um plano } \\
\text { global para cinco anos, institucionalização de uma política de recursos } \\
\text { humanos, modernização administrativa. }\end{array}$ \\
\hline 1996 & $\begin{array}{l}\text { Seminário de } \\
\text { planejamento } \\
\text { estratégico }\end{array}$ & $\begin{array}{l}\text { Sistematização do planejamento realizado com a participação de representantes } \\
\text { das instâncias administrativas e acadêmicas. Objetivou a elaboração, implantação, } \\
\text { acompanhamento e controle do planejamento estratégico. }\end{array}$ \\
\hline 1998 & $\begin{array}{l}\text { Conferência: } \\
\text { "Busca de } \\
\text { futuro - Uesb } \\
\text { e comunidade } \\
\text { construindo a } \\
\text { universidade do } \\
\text { 3o milênio" }\end{array}$ & $\begin{array}{l}\text { Objetivo: avaliar o papel da Uesb e projetar os rumos da instituição para } \\
\text { os próximos } 22 \text { anos. O evento foi realizado com membros dos três } \\
\text { segmentos da comunidade universitária, lideranças políticas e regionais, } \\
\text { empresários, representantes do poder público, de ONGs e outros } \\
\text { segmentos da sociedade. }\end{array}$ \\
\hline 1998 & $\begin{array}{l}\text { Conferência: } \\
\text { "Busca de } \\
\text { prioridades } \\
\text { - valorização } \\
\text { dos seus talentos } \\
\text { humanos" }\end{array}$ & $\begin{array}{l}\text { Discutir a elaboração de uma política de RH. Os participantes eram } \\
\text { representantes dos segmentos docente e técnico-administrativo, do poder } \\
\text { público estadual, profissionais da área de RH e de outras instituições. } \\
\text { Prioridade: elaboração de um programa de modernização para cinco anos } \\
\text { (1998-2003). }\end{array}$ \\
\hline 1998 & $\begin{array}{l}\text { Plano de } \\
\text { desenvolvimento } \\
\text { institucional } \\
\text { - campi de } \\
\text { Itapetinga e Jequié }\end{array}$ & $\begin{array}{l}\text { Documento orientador das políticas acadêmico-administrativas para o } \\
\text { período de } 1998 \text { a } 2002 .\end{array}$ \\
\hline 1999 & $\begin{array}{l}\text { Plano de } \\
\text { gestão e plano } \\
\text { de atividades } \\
-1999-2003\end{array}$ & $\begin{array}{l}\text { Define } 13 \text { objetivos gerais da gestão para o período de } 1999 \text { a 2003: } \\
\text { destaca-se no objetivo IV (política de recursos humanos) a justificativa para } \\
\text { implementação de um programa de modernização administrativa para a } \\
\text { área de RH. Os itens V (reestruturação organizacional) e VI (modernização } \\
\text { administrativa e acadêmica) tratam especificamente dos esforços } \\
\text { modernizantes a serem propostos para o período 1999-2003. }\end{array}$ \\
\hline
\end{tabular}

Fonte: Pesquisa documental. 
Foram inúmeras as iniciativas para decidir e implementar ações de modernização na Uesb, prolongando-se por quase uma década. Pereira Filho e colaboradores (2002), em sua análise sobre a proposta do orçamento participativo na Uesb, consideram que as iniciativas elencadas acima não conseguiram extrapolar a intenção das mesmas. A elaboração de estratégias capazes de integrar objetivos de uma mudança mais ousada para enfrentar os limites e as resistências exigiu, portanto, uma ação de maior fôlego por parte dos gestores públicos. Ou seja, estratégias de intervenção que pudessem responder à necessidade de modelos institucionais mais aperfeiçoados e práticas de implementação geradas em torno de consenso e participação. Os dois projetos em foco neste artigo retratam, justamente, as duas iniciativas mais bem estruturadas de modernização da Uesb.

\section{Implantação de um novo modelo de desenvolvimento gerencial da Uesb}

O projeto contempla a implantação de um novo modelo gerencial e foi elaborado a partir do diagnóstico produzido nos seminários de planejamento institucional e de recursos humanos realizados no período 1996-98. Apontou para a necessidade de modernizar a gestão da universidade, particularmente os recursos humanos. Estimulado pelo lançamento do Edital no 1/99 do Ministério da Educação e Cultura (MEC), por meio do Programa Especial de Projetos Destinados à Modernização e Qualificação Institucional do Ensino Superior, o projeto foi iniciado em 1999. A despeito do programa do MEC não ter disponibilizado, de fato, recursos financeiros para a Uesb, esta deu continuidade à proposta de um projeto de modernização.

O projeto propõe delinear um novo modelo gerencial centrado no desenvolvimento e na qualificação dos recursos humanos a curto prazo. Como objetivo paralelo, de mais longo prazo, propõe desenvolver uma nova cultura de recursos humanos, o que pressupõe, inclusive, uma mudança de mentalidade e o rompimento com as práticas de gestão vigentes. Outro dado que transparece é o da descentralização da gestão de RH que se opõe a uma perspectiva que privilegia uma visão cartorial de conduta em detrimento ao atendimento dos aspectos normativos e regimentais. O projeto visou implantar um modelo de gestão que integrasse a melhoria do desempenho dos níveis gerenciais com o aperfeiçoamento dos serviços prestados à sociedade - ensino, pesquisa e extensão. Portanto, um modelo que não se limite à área de administração de pessoal, mas que se estenda a uma concepção ampliada de gestão universitá- 
ria. Ao mesmo tempo, ao longo do texto do projeto, reafirma-se o papel da administração de recursos humanos em termos da estrutura do quadro de pessoal, aplicação de RH, manutenção, desenvolvimento e controle, o que, de fato, são as atividades de RH nos próprios moldes atuais. Isso mostra, do ponto de vista da formulação do texto da proposta, certa imprecisão sobre a relação entre descentralização e implementação das novas políticas de gestão.

Os temas abordados pelo modelo gerencial procuram cobrir, extensivamente, todos os aspectos da vida da organização universitária, reestruturando não somente os espaços, as esferas e os ordenamentos organizacionais, mas também a capacidade de participação ativa dos membros da instituição em cada etapa das atividades e dos trabalhos. Os objetivos específicos delineados na proposta são: diagnosticar o perfil dos gestores e das funções que compõem a sua estrutura organizacional; promover pesquisa de clima organizacional; identificar a necessidade anual de qualificação profissional; criar um núcleo avançado de qualificação e aperfeiçoamento do quadro de pessoal para a implementação do programa de avaliação de desempenho, gestão de competências e plano de sucessão de funções; implantar uma instância reguladora e orientadora da nova política de recursos humanos; preparar as chefias/dirigentes para uma nova dinâmica gerencial, melhorando o desenvolvimento institucional; preparar os servidores para se adequarem à nova dinâmica gerencial.

As variáveis para a elaboração de um plano de trabalho para implementar o projeto são descritas na proposta, como segue: fortalecimento da cultura de desempenho; ênfase no treinamento para liderança, (re)qualificação profissional e desenvolvimento gerencial; ênfase nas questões éticas do mundo moderno, como relações de gênero, ética pública, habilidades específicas de gestão, cidadania e justiça social; ênfase na construção de um novo modelo de desenvolvimento gerencial; ênfase na capacidade de autogestão e mobilização do potencial humano; flexibilidade administrativa.

Como variáveis do plano de trabalho estão os elementos de natureza mais geral que se sobrepõem aos próprios objetivos. Conceitos como ênfase, flexibilidade e fortalecimento introduzem proposições abrangentes que não discriminam minuciosamente os dados que formarão parte da estratégia da ação prática para implementar cada um dos fatores. O próprio texto do projeto não orienta suficientemente sobre o aspecto prático e de intervenção de suas proposições originais, isto é, dos próprios objetivos. Mas, ao descrever as atividades que devem ser implementadas para a viabilização da proposta, o modelo gerencial indica as seguintes ações: levantamento do perfil dos gestores e das funções que compõem a estrutura da organização; realização de uma 
pesquisa de clima organizacional; implementação do programa de avaliação de desempenho; criação do núcleo avançado de aperfeiçoamento e qualificação de recursos humanos; implantação da câmara orientadora de recursos humanos; execução do programa de capacitação direcionada.

Os resultados esperados, anunciados no projeto, também caracterizam situações bastante gerais, não as vinculando às variáveis e aos indicadores de controle da própria ação de gestão do novo modelo de desenvolvimento gerencial sugerido: mudança de cultura organizacional e maior diversidade de práticas de gestão entre os setores administrativos e acadêmicos; maior eficiência na alocação e direção do corpo técnico-administrativo; contribuição para a eficiência/eficácia dos serviços prestados; fortalecimento da articulação entre os objetivos gerais da instituição e a execução das atividades; descentralização da gestão de recursos humanos.

Percebe-se um considerável grau de generalidade nos resultados esperados de modernização gerencial. Na realidade, a sobreposição entre os diversos fatores relevantes de elaboração do projeto — objetivos, ações, variáveis e resultados - sugere que a motivação por um projeto de modernização de gestão deparou-se com duas situações paralelas: a dificuldade política de definir e decidir objetivos e as medidas correlatas demandadas, pois isso exigiria assumir posição e compromisso definidos mediante a proposta a ser aprovada em plenárias representativas. O segundo aspecto diz respeito ao fato que decidir-se por políticas e medidas bem delineadas expõe com clareza posições político-administrativas na esfera da gestão que abarcam os conflitos e tensões que temas e necessidades dessa natureza envolvem. Ou seja, pela análise geral da proposta, pode-se inferir que a virtude foi introduzir a ideia da necessidade de mudança e de organizar um consenso bem amplo em torno de um objetivo geral; mas, ao se manter em um nível propositivo bem genérico, a proposta foi incapaz de produzir um campo de negociação interno capaz de transformar o ideário geral em uma ação efetiva para a sua implementação.

\section{Orçamento participativo na Uesb: uma prática democrática}

O segundo projeto (agora chamado proposta de OP) volta-se para uma proposição que enfoca a questão orçamentária e suas implicações na gestão. No Brasil, a prática de elaboração do orçamento público com a participação direta da sociedade nas suas diversas fases foi instituída pelo governo do Partido dos Trabalhadores em Porto Alegre, em 1989, tornando-se um modelo de gestão participativa de referência nacional e internacional que tem como aspectos principais a capacidade de intervenção da população na identificação de ne- 
cessidades, na escolha de prioridades e na decisão quanto à aplicação de parte dos recursos municipais (Fadul, 2000).

O projeto de OP objetivava responder a uma reivindicação da comunidade acadêmica por um maior envolvimento na formulação de políticas institucionais, inclusive do processo decisório, da definição de prioridades e da ampliação das próprias instâncias de decisão. O projeto foi apresentado em 2001, para ser a base de condução do orçamento de 2002; supõe a participação de diversas instâncias e uma maior intervenção nas plenárias de tomada de decisão. Seu papel seria de agregar um processo formativo e político que transcenderia o elemento técnico do orçamento, olhando o planejamento como um todo, para repensar o próprio modelo de gestão universitária.

$\mathrm{O}$ orçamento a ser discutido por meio do projeto de OP contempla o item investimento, que integra o conjunto de despesas relativas a obras e projetos. O modelo proposto nessa iniciativa encontra aqui duas grandes diretrizes: compatibilizar as formas de participação dos diferentes segmentos universitários com o modelo orçamentário definido pela Secretaria do Estado da Bahia; e articular os objetivos institucionais propostos pelo reitorado do período com as prioridades definidas pela comunidade universitária. Considera-se que a última diretriz seja mais complexa porque trata do item projeto, em que são agregadas as despesas diretamente relacionadas com a realização das atividades-fins da instituição. Tais diretrizes apontam para desafios de ordem técnico-operacional e política e retratam as preocupações e interesses da comunidade universitária na definição de prioridades.

No caso da Uesb, a ideia de orçamento participativo é entendida como um fórum de tomada de decisão e, ao mesmo tempo, um processo de educação política capaz de influenciar uma consciência de responsabilidade e compromisso, valores que fortalecem a própria participação na organização, ou o que pode ser chamado de democracia institucional. Os objetivos básicos de orientação do projeto de OP convergem para o estabelecimento de novas relações na elaboração do orçamento e a constituição do fórum do orçamento participativo como instância de controle, acompanhamento e fiscalização da aplicação dos recursos. Assim, os objetivos gerais elencados são: definir prioridades com base na readequação dos objetivos às demandas e necessidades da comunidade universitária; elaborar, com ampla participação e debate, o orçamento institucional, definindo valores de receita e prioridades; constituir relações menos hierárquicas e participativas de tomada de decisão; constituir o fórum do orçamento participativo.

O processo de operacionalização da participação dos segmentos é sugerido em três momentos: o primeiro descreve a identificação das prioridades, definidas em assembleias das categorias docente, discente e técnico-adminis- 
trativa. O segundo descreve a sistematização e definição final das prioridades em plenária geral. No terceiro momento, propõe-se uma assembleia geral do fórum do orçamento participativo para a compatibilização das decisões, por meio da Comissão do Orçamento Participativo (COP). Concluídas essas etapas, propõe-se que o documento final seja encaminhado para o Conselho Universitário (Consu), órgão máximo de deliberação, para referendar aquelas decisões. A expectativa de resultados com a adoção dessa prática participativa relaciona-se com a mudança do padrão de planejamento orçamentário e de aplicação dos recursos. Indica que alterações na gestão e mudanças na estrutura administrativa repercutem nas atividades-fins da instituição. Soma-se a isso, a democratização da gestão técnica e administrativa que articula e estabelece novas prioridades de trabalho.

Mesmo considerando as distinções de conteúdo e natureza apresentadas, a análise dos dois projetos de modernização e das entrevistas realizadas possibilitaram identificar uma convergência em torno de quatro eixos básicos que denotam as diretrizes e os princípios propostos para ações em modelo de gestão neste caso específico. O quadro 2 equaciona os elementos comuns identificados nos dois projetos de modernização da Uesb.

$$
\text { Quadro } 2
$$

Eixos de convergência dos projetos de mudança e modernização

\begin{tabular}{|c|c|c|}
\hline $\begin{array}{l}\text { Eixos de convergência } \\
\text { dos projetos }\end{array}$ & Modelo gerencial & Proposta de OP \\
\hline $\begin{array}{l}\text { Redefinição da ação } \\
\text { administrativa }\end{array}$ & $\begin{array}{l}\text { (Re) qualificação dos gestores, } \\
\text { desenvolvimento de uma nova } \\
\text { cultura de administração de RH, } \\
\text { gestão descentralizada de RH. }\end{array}$ & $\begin{array}{l}\text { Constituição de relações } \\
\text { democráticas e participativas na } \\
\text { tomada de decisão, estrutura } \\
\text { colegiada de decisão. }\end{array}$ \\
\hline $\begin{array}{l}\text { Surgimento de novos } \\
\text { valores }\end{array}$ & $\begin{array}{l}\text { Fortalecimento de uma cultura de } \\
\text { desempenho, ênfase nas habilidades } \\
\text { específicas e de gestão, na } \\
\text { capacidade de autogestão. }\end{array}$ & $\begin{array}{l}\text { Construção de um modelo de } \\
\text { gestão participativa, compartilhada. }\end{array}$ \\
\hline $\begin{array}{l}\text { Fortalecimento de } \\
\text { valores sociais múltiplos }\end{array}$ & $\begin{array}{l}\text { Cooperação, participação, } \\
\text { consciência institucional, práticas } \\
\text { colaborativas, flexibilidade } \\
\text { administrativa. }\end{array}$ & $\begin{array}{l}\text { Ética pública, transparência, } \\
\text { austeridade administrativa, } \\
\text { democracia interna, cidadania. }\end{array}$ \\
\hline $\begin{array}{l}\text { Ampliação das instâncias } \\
\text { decisórias }\end{array}$ & $\begin{array}{l}\text { Criação do Conselho Orientador de } \\
\text { Recursos Humanos (Corh) e Núcleo } \\
\text { Avançado de Aperfeiçoamento e } \\
\text { Qualificação. }\end{array}$ & $\begin{array}{l}\text { Criação do Fórum e da Comissão do } \\
\text { Orçamento Participativo (COP). }\end{array}$ \\
\hline
\end{tabular}

Fonte: Pesquisa de campo. 
No primeiro eixo, observa-se que no modelo gerencial a redefinição da ação administrativa é proposta por meio de uma gestão descentralizada de recursos humanos. O modelo seria fortalecido com o desenvolvimento de uma cultura de administração de RH com ênfase em: aperfeiçoamento das atividades-meio, desenvolvimento de habilidades gerenciais, fortalecimento de uma cultura de desempenho e implementação de um programa de qualificação para os servidores. No caso do projeto de OP, o modelo propõe estabelecer relações regidas por princípios participativos no processo de tomada de decisão. A esfera de constituição dessas relações seria a estrutura colegiada de decisão.

Dois outros eixos - surgimento e fortalecimento de valores sociais se entrecruzam nos projetos propostos. Afirmam que podem implantar uma gestão com ênfase em valores pouco cultivados na administração das universidades públicas brasileiras. Estas estão totalmente ligadas aos órgãos da administração pública direta, ministérios e secretarias de governo, realimentando a carga cultural e normativa do serviço público (Mattos, 1991). Valores como cooperação, participação, transparência, ética pública, austeridade administrativa, democracia interna e cidadania requalificam a temática da gestão universitária e as práticas nela presentes. Vale ressaltar que, nas entrevistas realizadas, as adjetivações aos atributos da racionalidade técnica (Sobrinho, 1999), como requisitos da gestão universitária, aparecem com pouca recorrência entre os entrevistados. Essa observação é pertinente diante do controverso debate sobre a prevalência dos princípios da lógica produtivista de mercado na gestão universitária existente no interior de setores do Estado, nas próprias instituições acadêmicas, na sociedade e, particularmente, entre os organismos multilaterais que financiam políticas públicas educacionais e o governo (Fundo Monetário Internacional e Banco Mundial). O último eixo — ampliação das instâncias decisórias — articula-se com a criação de estruturas colegiadas de decisão.

\section{A dinâmica de implantação dos projetos: entre o planejado e o realizado}

\section{A participação como princípio orientador da gestão}

A participação diz respeito à demanda, por parte da comunidade acadêmica, por espaços participativos de representação e decisão sobre os diversos interesses expressos pelos atores. A demanda por maior participação na gestão 
universitária aparece até mesmo no interior dos movimentos estudantil e sindical, docente e técnico-administrativo, no sentido de reestruturar as instâncias decisórias da universidade. No centro das discussões, a participação não se limita à representação das categorias nos órgãos, mas refere-se à própria redefinição dos espaços para uma política de integração e de canais de ação/ decisão. Esse é um aspecto bem discutido na literatura sobre administração universitária, e um ponto fulcral na definição de um modelo de gestão para as organizações, particularmente as públicas no Brasil.

Embora os projetos estudados guardem um núcleo comum quanto ao ideal de uma gestão permeável ao diálogo, nota-se que o termo participação comporta diferentes acepções entre os entrevistados. Para aqueles que fizeram parte do modelo gerencial, a participação se caracteriza, a nosso ver, pela diluição de responsabilidades das atividades relacionadas com a área de recursos humanos para os setores administrativos. O propósito de institucionalizar uma cultura de recursos humanos que seja difusa entre os demais setores da instituição reforça-se no princípio da participação e assume o significado de descentralização de funções. Apesar de a participação ser mencionada por todos os entrevistados, em nenhum dos depoimentos explicita-se as estratégias e políticas para a sua concretização. Essa constatação aponta para uma noção fraca de participação, já que não há clareza quanto aos modos como ela se efetivaria, o que, em última instância, significa não conseguir avançar para além do enunciado geral do princípio.

No projeto de OP, o ideal da participação relaciona-se com a democracia interna na universidade, definida como estatuto de cidadania; pauta-se no argumento de que as decisões devem ser tomadas pelos indivíduos afetados por elas. O conteúdo do projeto faz analogia a alguns dos princípios orientadores do orçamento participativo na esfera da gestão dos municípios. Entre eles, destacam-se: transparência, descentralização, otimização, austeridade e participação direta na definição e aplicação dos recursos públicos. Diferentemente dos entrevistados do projeto modelo gerencial, os depoentes que atuaram na formulação do projeto de OP são unânimes em afirmar que a participação é necessária para romper com o atual modelo de gestão e deveria ser instituída através de uma política que associasse fóruns ampliados de decisão com canais de participação dos diferentes segmentos. Observa-se nos depoimentos que o sentido mais forte atribuído ao princípio da participação é o de corresponsabilidade, cogestão, "cumplicidade" entre quem decide e quem executa.

Essas distintas acepções revelam que, entre os gestores entrevistados, o princípio comum apresenta um continuum com diferentes gradações. Uma avaliação possível para esses significados diferenciados é que eles são coe- 
rentes com as formas como a participação é entendida pelos entrevistados, que engendram comportamentos e práticas distintas na condução da gestão e se inscrevem nas variadas interpretações que a noção acomoda. Para Sani (citado por Bobbio, Mateucci e Pasquino, 2000), é possível reconhecer que os níveis de participação dos indivíduos ou grupos se dão sob formas e condições diferenciadas, de acordo com o contexto. Embora analise a participação sob a perspectiva das relações entre o estado e a sociedade civil, considera que ela se insere em um plano que se estende desde a presença até a participação no sentido estrito. Já Carvalho (1998) adverte para a generalização do discurso da participação cujo conteúdo explicita significados e projetos distintos. Ressalta que a abrangência da mesma (quem deve participar e qual a amplitude desejável) constitui um divisor de águas que passa a explicitar projetos mantidos sempre um tanto obscuros numa permanente disputa de significados.

\section{Os projetos como estratégias de renovação da gestão}

Com a finalidade de identificar os principais aspectos dos planos de modernização propostos para a Uesb, foi pedido aos entrevistados que discorressem sobre a relevância do projeto como estratégia de renovação. Para o modelo gerencial, elegeram quatro aspectos centrais: descentralização da gestão, qualificação profissional, elaboração conjunta da proposta de modernização e reestruturação organizacional. $\mathrm{O}$ aspecto que aparece com maior recorrência nas entrevistas é a necessidade de inculcar, entre os gestores e os funcionários uma compreensão de que seu papel na instituição exige qualificação para o desenvolvimento das atividades inerentes às próprias funções. Observa-se nos depoimentos que essa relação é entendida como uma relação "causa-efeito". Na literatura, esta preocupação está presente e vem do que Buarque (1994) denomina divórcio entre a administração e os professores.

Outro aspecto destacado nos depoimentos é o consenso estabelecido de que deve haver uma conformidade de ideias e opiniões entre os próprios gestores a partir de análise das práticas existentes, revistas à luz do princípio da participação, sem recorrer à aplicação de modelos estabelecidos. O quarto e último aspecto destacado relaciona-se com a alteração da estrutura formal, pela criação de órgãos deliberativos (conselhos), qualificados como espaços participativos de gestão. Nota-se que os entrevistados não associam os aspectos relevantes da proposta às possibilidades concretas de sua institucionalização, como pretendia o projeto. Para eles a concretização do modelo se daria pari passu à definição das estratégias de implementação. 
Entre os aspectos relevantes do projeto de OP, encontram-se a referência à alocação de recursos, transparência, otimização, austeridade nos gastos públicos e democratização da gestão. Fávero (1983) chama a atenção para o quanto esse aspecto é complexo e, ao mesmo tempo, desafiador para a gestão da universidade. Pela sua própria natureza, a instituição comporta diferentes grupos de autoridade e grupos de influência que reivindicam participação no processo decisório. Sob essa perspectiva, as relações de poder não assumem um caráter meramente administrativo ou acadêmico; definem-se, sobretudo, como uma questão de política interna. A pergunta "quem decide?" apresenta variadas respostas que nem sempre estão explícitas ou são visíveis no jogo decisório.

Comparativamente ao modelo gerencial, o projeto de OP avançou no sentido de detalhar as estratégias e canais de participação da comunidade universitária, revelando, nos depoimentos, como as práticas a serem adotadas se conformariam nesse modelo de gestão. O conjunto das principais características apresentadas nesse item permitiu avaliar os pontos de ruptura necessários à modernização na Uesb. Para organizar a análise, as respostas obtidas foram classificadas em duas vertentes: na primeira estão proposições de mudança na estrutura formal (criação de conselhos e fóruns), de ações de qualificação para $\mathrm{RH}$, programa de avaliação de desempenho e de competências e o plano de sucessão de funções. Na segunda vertente foram classificadas as informações que caracterizam uma modernização para além de ações práticas dirigidas, pois os depoentes entendiam que a modernização não se restringe à adoção de tecnologias modernas, novos procedimentos de trabalho ou modificações na estrutura organizacional, mas requer reformulação das bases de valores e condutas sobre as quais se assentam as mudanças.

A unificação dos discursos sobre o tema no decorrer das entrevistas revela ser preciso romper com o sentimento de imobilismo. Seria necessário, portanto, o envolvimento e a crença dos membros da universidade nas propostas encaminhadas. A esse respeito, Vasconcelos (1995) afirma que é condição sine qua non para o êxito de um plano que os envolvidos em sua execução tenham condições de compreendê-lo, julgá-lo importante, inclusive de crer na proposta, convictos das possibilidades de produzir mudanças. Pode-se dizer que a modernização requer uma mudança de mentalidade, pois não se reduz às dimensões técnicas e materiais, mas depende de valores e crenças renovadores e do suporte institucional. Ou seja, é importante o modo como os indivíduos incorporam os valores contidos nos projetos modernizantes, para além do contexto ao qual estão vinculados. Essa argumentação reconhece a complexidade dos processos de mudança, afastando-se da ideia de um processo unilinear e homogêneo, orientado por uma lógica unicamente pragmática que 
concebe a organização como um universo fechado e separado do seu contexto social, como ressalta Barbosa (1999).

Dois aspectos são centrais nesse debate: o rompimento com as práticas internalizadas e reproduzidas no cotidiano e a adoção de novas práticas que se conformam com os propósitos da modernização almejada. Portanto, há a necessidade de alterações profundas, tanto na estrutura quanto nos padrões de atitude e de comportamento dos indivíduos. Situando a questão no âmbito da organização universitária, Trigueiro (1999) reconhece que os processos de inovação requerem ampliar a reflexão sobre os mais diferentes aspectos de cultura, estrutura, funcionamento, normas e valores que orientam os padrões de conduta dos membros da universidade; requerem, também, verificar quais desses valores e princípios reguladores estão ancorados no contexto contemporâneo plural de se entender uma organização.

\section{"Remando contra a maré": fatores que limitaram a implementação das propostas de modernização}

A análise de conteúdo das entrevistas permitiu identificar alguns fatores que limitaram o encaminhamento das propostas de modernização. Considerando que os entrevistados apontaram para uma multiplicidade de aspectos que obstaculizaram a mudança, os dados dos depoimentos sobre essa questão foram classificados em três dimensões: institucional, sociocultural e política. Essa tipologia toma por referência as observações feitas por Leitão (1990), Hardy e Fachin (2000), Trigueiro (1999) e Rodrigues (1985) sobre a perspectiva de análise das organizações universitárias que integra o funcionamento do sistema organizacional com as relações entre os atores e a visão dos mesmos sobre como agir em relação ao seu papel na organização.

A dimensão institucional inclui os aspectos que se situam dentro da própria organização ou, ainda, que estejam fora dela, tais como: legais, financeiros, comunicação interna, estrutura organizacional e outros aspectos correlatos. A dimensão política se refere aos limites identificados nas relações entre indivíduos e grupos, as tensões que se estabeleceram, assim como a fragmentação e os conflitos entre os membros da administração central e grupos presentes na organização universitária.

Na dimensão sociocultural estão agrupados os discursos que remetem à existência de hábitos, valores e crenças presentes no ambiente organizacional, e se reportam à sociedade como um todo; reproduzem-se no cotidiano da Uesb e condicionam as práticas de gestão de seus membros nos aspectos que obs- 
taculizam a modernização. Analisar essa dimensão é procurar compreender os limites de ordem subjetiva da modernização e que se manifestam nas condutas objetivas, como resultado dos diferentes significados que os indivíduos dão à mudança. No quadro 3 estão reunidos dados que exemplificam como os depoimentos sobre os principais fatores que obstaculizaram a implementação das propostas em estudo foram caracterizados pelos depoentes.

\section{Quadro 3}

\section{Fatores que limitaram a implementação dos projetos}

\begin{tabular}{|c|c|}
\hline Dimensão & Fatores indicados nas entrevistas \\
\hline Institu & $\begin{array}{l}\text { "faltou tempo, porque outras demandas da universidade roubaram tempo do projeto. A } \\
\text { gente percebe que algumas ações foram desenvolvidas, mas faltou realmente elas serem } \\
\text { colocadas em prática" (entrevistado 7). } \\
\text { "como entrave é a própria estrutura da universidade" (entrevistado 3). } \\
\text { "o caráter inovador da proposta com a estrutura gerencial existente na universidade" } \\
\text { (entrevistado 4). }\end{array}$ \\
\hline Política & $\begin{array}{l}\text { "Havia esta contradição daqueles que queriam e outros que ficavam com medo de participar. } \\
\text { Não mostravam interesse ou achavam que era uma coisa que nós queríamos implantar } \\
\text { para mudar uma realidade sem levar em consideração as condições da universidade" } \\
\text { (entrevistado 6). } \\
\text { "É a questão da diluição do poder. Isso está muito claro. As pessoas não querem realmente abrir } \\
\text { mão do poder e isso dentro do ambiente universitário não é diferente" (entrevistado } 2 \text { ). }\end{array}$ \\
\hline Sociocultural & $\begin{array}{l}\text { "olha a maior resistência ao projeto dentro de uma instituição universitária, por incrível que } \\
\text { pareça, foi a resistência a uma metodologia de participação" (entrevistado 3). } \\
\text { "a resistência da meritocracia universitária que considera um absurdo você ampliar o } \\
\text { processo decisório para uma democracia participativa (...) uma resistência conservadora. } \\
\text { Uma meritocracia conservadora que resiste a qualquer possibilidade de mudança" } \\
\text { (entrevistado 3). }\end{array}$ \\
\hline
\end{tabular}

Fonte: Pesquisa de campo.

O fator institucional limitante que aparece com maior força é a atual estrutura da universidade - burocrática e centralizadora - que impede as inovações que pretendem que as decisões sejam socializadas. Embora as universidades sejam um ambiente onde se desenvolve inovações que se relacionam com as atividades-fim, graças à dinâmica constante da produção de conhecimento, o mesmo não pode ser dito em relação aos processos decisórios e administrativos e à estrutura interna das mesmas. Há imensas resistências que as tornam organizações extremamente conservadoras e infensas a mudanças (Trigueiro, 1999). Outros fatores mencionados foram: a falta de tempo 
para a implementação das propostas, o que permite concluir que as atividades demandadas pela burocracia sufocaram a iniciativa de inovação; a restrição financeira e as estratégias de comunicação adotadas que foram consideradas deficientes.

A dimensão política dos obstáculos aponta para as tensões entre indivíduos e grupos em relação a uma maior democratização do poder, isto é, a modificação das hierarquias e autoridades correspondentes (poder de decisão, peso nas votações etc.) e a maior horizontalização das relações de poder e trabalho entre os segmentos docente e administrativo, principalmente. Outras divergências referem-se à tensão sobre se estabelecer um consenso acerca de uma definição de estratégia para o modelo gerencial, havendo uma falta de entendimento e até mesmo dificuldades de discuti-la. Uma das justificativas sobre essa tensão foi a das críticas que qualificavam o projeto como mais próximo de preocupações de uma organização privada, tal como "modelo de iniciativa privada", "qualidade total na universidade", entre outros.

A tensão parece ter sido gerada pela ideia de competência e suas implicações sobre a de participação, agravada pelas divergências das diferentes concepções de participação mencionadas anteriormente. Isso remete à preocupação de Teixeira (2001) quanto à difícil relação entre participar e realizar as decisões por parte dos agentes que recebem um mandato. E, por último, constatou-se tensão em relação ao que se denominou conflito de concepção. Porque apesar da participação ser o ideal que orientou as duas propostas, um dos entrevistados sobre o modelo gerencial apontou como obstáculo à implementação do mesmo a própria democratização do processo, que diluía os esforços em direção a decisões mais claras e consequentes para uma ação de mudança.

Na perspectiva da dimensão sociocultural é unânime, entre os entrevistados, haver, na prática, uma resistência à modernização, herança de uma cultura conservadora que concebe o velho revestido do novo. É o principal obstáculo para o rompimento com as práticas de gestão cristalizadas entre os membros da Uesb. Essa constatação reforça o argumento de DaMatta (citado por Vasconcelos, 1995), quando afirma que as organizações não são sobrepostas em um determinado espaço, mas formam-se a partir dele, de um modo bem imbricado. Por essa razão, Vasconcelos (1995) considera que, no caso brasileiro, existem estruturas históricas paralelas que funcionam como elementos obstaculizadores aos esforços de modernização bem perceptíveis em diversos espaços das agências públicas.

Relacionada ao comportamento reticente a uma democratização do poder decisório é a resistência que a burocracia confere a mudanças no desenho 
do cargo, porque hierarquiza no plano funcional e iguala, quando necessário, nas relações pessoais. Retoma-se DaMatta (1997b:193) para explicar que tal resistência promove o que ele qualifica de "uma tremenda complexidade classificatória, um enorme sentimento de compensação e complementaridade, impedindo certamente a tomada de consciência social horizontal". De acordo com Wanderley (1999), com raras exceções, os processos dominantes de hierarquização e de burocratização enrijecem a estrutura organizacional. Além disso, formas implícitas ou manifestas de um poder centralizador e autoritário têm tornado as relações entre os membros da universidade opacas e desconfiadas. Tal complexidade aponta para as dificuldades na consolidação de uma gestão democrático-participativa, pois a universidade é também um espaço de reprodução das próprias condições de poder na sociedade, quer seja nas salas de aula, quer seja nas práticas de gestão ou nas relações entre agentes.

Traçando um paralelo entre as três dimensões analisadas, observa-se que a dimensão política associa-se à cultural no que diz respeito à explicitação dos conflitos. É importante registrar que houve entre os depoentes uma concordância em falar sobre os elementos consensuais das propostas; no entanto, durante as entrevistas, os conflitos não foram tratados com a mesma espontaneidade ou intensidade. Esse comportamento reticente observado na fala dos depoentes encontra apoio para a análise em DaMatta (1997b) e Santos (1993) que afirmam que a sociedade brasileira encontra dificuldades em expressar relações que não sejam apoiadas num cunho afetivo e, consequentemente, há uma forte propensão a dissimular conflitos. No entanto, reconhece-se que todo processo de mudança gera instabilidade no grupo, implica choques de interesses e envolve tensões, não raro produzindo impasses como resultado da interação.

Vale ressaltar que nas três dimensões apresentadas para se analisar aspectos limitantes dos projetos é baixo o grau de participação dos membros da universidade na sua implementação. O que leva a concluir que o grau de engajamento dos indivíduos determinou os avanços e, em última instância, recuos na implementação das propostas. Os obstáculos a iniciativas de modernização parecem estar presentes nas pessoas, na mentalidade dos que expressam diferentes modos de gerir e entender a instituição. Mas, encontram-se, também, presentes na estrutura verticalizada de poder, na tradição burocrática estanque e, sem dúvida, na pouca experiência de gestão participativa que ainda é um desafio na administração de uma organização voltada para o ensino superior.

Além da análise sobre os fatores limitadores das propostas, chamou a atenção alguns depoimentos relativos à implementação do projeto de OP que 
expressam um comportamento reticente, um sentimento de desencanto envolvido de falta de confiança nas mudanças. Indagou-se sobre o compromisso dos indivíduos, o grau de adesão dos membros da Uesb às propostas, conforme a percepção dos entrevistados. Isso foi observado a partir dos atributos relativos à cultura política e que formam o capital social: o senso de confiança, de cooperação e de participação. Como argumenta Putnam (2000), esses elementos estão relacionados e são fundamentais nos processos de mudança, pois quanto mais elevada a confiança maior é a cooperação e o senso de responsabilidade compartida. Fazendo um paralelo com o círculo virtuoso descrito pelo autor, nota-se que o envolvimento reticente dos membros da organização acadêmica impediu que a confiança se consolidasse e produzisse a cooperação, prejudicando a participação dos envolvidos na implementação das propostas de modernização. Como se pode concluir, os diferentes níveis de envolvimento demonstrados não foram suficientes para implicar uma estratégia modernizadora, impedindo que a complementação do ciclo de ação resultasse em mudanças efetivas na gestão da Uesb.

\section{Considerações finais}

O argumento que orientou este artigo parte do pressuposto de que a gestão não ocorre em um vácuo sociocultural. Assim, reafirmando as posições teórico-metodológicas da pesquisa, pode-se dizer que a ação dos diferentes sujeitos é influenciada pelo contexto em que vivem, ainda que se considere que essa relação ocorra num movimento pendular, ou seja, indivíduos são influenciados pela cultura e pelos valores que os circundam, bem como influenciam, eles próprios, seu ambiente. Tal argumentação encontra apoio em Barbosa (1999), Trigueiro (1999), DaMatta (1997a, 1997b) e Vasconcelos (1995).

As transformações exigidas por qualquer esforço de modernização não requerem, apenas, impactar o plano objetivo dos fenômenos sociais, ou seja, não se limitam a mudanças nos sistemas que estruturam a vida em sociedade ou o padrão de autoridade, a reordenação da divisão do trabalho, as novas tecnologias e linguagens comunicativas, a incorporação de novos métodos de controle ou de novos atores no processo de decisão. Requer, sim, de forma crucial, mudanças de crenças, percepções e atitudes por parte dos indivíduos e grupos que podem influir, negativa ou positivamente, na produção e aceitação de novas formas de agir. Reconhecendo que um processo de modernização é complexo e não linear, torna-se evidente a relevância do papel que os diferentes atores ocupam em relação a inovações. É por meio desses agentes que as 
ações assumem significados distintos e, como revela este artigo, tomam como referência os valores e padrões de conduta presentes na própria sociedade e os reproduzem no âmbito das organizações. Portanto, modernizar estas últimas depende, também, de mudanças no próprio modo de pensar e agir nos ambientes sociais da vida cotidiana e cívica.

A análise produzida neste artigo permite inferir que a bagagem cultural, técnica, política e social da qual o indivíduo é portador, fruto da sua experiência na vida social e na organizacional, resulta em atitudes facilitadoras ou obstaculizadoras diante de experiências de modernização. Os depoimentos revelam que os obstáculos à modernização engendram um conjunto de significados diferentes para os atores, compondo um mosaico em que as mudanças de fundo são as que sofrem fortes resistências, permanecendo a ação organizacional limitada a intervenções tópicas, que não se defrontam com as tensões e os conflitos mais significativos desta complexa estrutura organizacional - a universidade pública.

Pode-se dizer que a ação voltada para a institucionalização de uma prática modernizadora requer considerar o grande peso do fator humano - cultura e mentalidade - que pode se tornar óbice a mudanças. Dois aspectos centrais devem ser levados em conta quando são iniciados esforços de modernização: a mudança de mentalidade dos envolvidos e a capacidade de participar em processos decisórios mais consensuais, o que exige tempo e habilidade política, envolvendo esforços prolongados e contínuos para o rompimento com práticas instituídas de caráter limitador. Há de se considerar, também, compromissos com a mudança de longo prazo para influenciar as condutas dos sujeitos que atuam nas mais diversas instituições. Essas considerações tornam-se particularmente relevantes para uma instituição universitária pública que tem o papel de gerar saber e conhecimento que contribuam para provocar transformações na própria sociedade em que está inserida.

\section{Referências bibliográficas}

BARBOSA, Lívia. Igualdade e meritocracia: a ética do desempenho nas sociedades modernas. 2. ed. Rio de Janeiro: FGV, 1999.

BOBBIO, Norberto; MATTEUCI, Nicola; PASQUINO, Gianfranco. Dicionário de política. 5. ed. Brasília: Universidade de Brasília; São Paulo: Imprensa Oficial do Estado, 2000.

BUARQUE, Cristovam. A aventura da universidade. São Paulo: Unesp; Rio de Janeiro: Paz e Terra, 1994. 
CARVALHO, Maria do Carmo A. A. Participação social no Brasil hoje. Pólis Papers, n. 2, 1998.

CATANI, Afrânio Mendes; DOURADO, Luiz F; OLIVEIRA, João F. Natureza jurídica, organização acadêmica e gestão universitária. In: SGUISSARDI, Valdemar; SILVA JR., João dos Reis (Orgs.). Educação superior: análise e perspectivas de pesquisa. São Paulo: Xamã, 2001.

DAMATTA, Roberto da. A casa \& a rua: espaço, cidadania, mulher e morte no Brasil. 5. ed. Rio de Janeiro: Rocco, 1997a.

. Carnavais, malandros e heróis: para uma sociologia do dilema brasileiro. 6. ed. Rio de Janeiro: Rocco, 1997b.

FADUL, Élvia. Orçamento participativo: limites e contradições de um modelo decisório inovador. In: IVO, Anete Brito L. (Org.). O poder da cidade: limites da governança urbana. Salvador: Edufba, 2000.

FÁVERO, Maria de Lurdes de A. Universidade: poder e participação. Educação \& Sociedade, Cortez, n. 16, dez. 1983.

GODOY, Arilda S. Introdução à pesquisa qualitativa e suas possibilidades. Revista de Administração de Empresas, São Paulo, v. 35, n. 2, mar./abr. 1995.

HARDY, Cynthia; FACHIN, Roberto. Gestão estratégica na universidade brasileira: teoria e casos. 2. ed. Porto Alegre: UFRGS, 2000.

LEITÃO, Sérgio Proença. Estrutura, cultura e desempenho organizacional na universidade. Revista de Administração Pública, Rio de Janeiro, v. 24, n. 1, nov. 1989/jan. 1990.

MATTOS, Pedro Lincoln. Administração e mudança nas universidades federais: questões-chave. Revista Educação Brasileira, Brasília, v. 13, n. 26, 1991.

PENTEADO, Silvia Ângela Teixeira. À procura de um foco para o fazer universitário. In: Identidade e poder na universidade. São Paulo: Cortez; Santos: Unisanta, 1998.

PEREIRA FILHO, Waldenor Alves et al. Orçamento participativo na universidade: uma experiência de gestão compartilhada. Revista Pré-Textos para Discussão, Salvador, ano VII, n. 12, 2002.

PUTNAM, Robert. Comunidade e democracia: a experiência da Itália moderna. 2. ed. Rio de Janeiro: FGV, 2000.

RICHARDSON, Roberto Jarry. Pesquisa social: métodos e técnicas. São Paulo: Atlas, 1999. 
RODRIGUES, Suzana Braga. Processo decisório em universidades: teoria III. Revista de Administração Pública, Rio de Janeiro, v. 4, n. 19, out./dez. 1985.

SANTOS, Boaventura de Souza. Da idéia de universidade à universidade de idéias. In: Pela mão de Alice: o social e o político na pós-modernidade. 6. ed. São Paulo: Cortez, 1999.

SANTOS, Wanderley Guilherme dos. Fronteira do estado mínimo - indicações sobre o híbrido institucional brasileiro. In: Razões da desordem. Rio de Janeiro: Rocco, 1993.

SOBRINHO, José Dias. Concepções de universidade e de avaliação institucional. In: TRINDADE, Hélgio (Org.). Universidade em ruínas: na república dos professores. Petrópolis: Vozes; Rio Grande do Sul: Cipedes, 1999.

TEIXEIRA, Elenaldo. Participação cidadã no poder local: algumas experiências no Brasil. In: $O$ local e o global: limites e desafios da participação cidadã. 2. ed. São Paulo: Cortez; Recife: Equip; Salvador: UFBA, 2001.

TRIGUEIRO, Michelangelo Giotto Santoro. Universidades públicas: desafios e possibilidades no Brasil contemporâneo. Brasília: UnB, 1999.

UESB (Universidade Estadual do Sudoeste da Bahia). Projeto implantação de um novo modelo de desenvolvimento gerencial na Universidade Estadual do Sudoeste da Bahia (Uesb). Vitória da Conquista, jul. 1999.

. Orçamento participativo na Uesb: uma prática democrática. Vitória da Conquista, jun. 2001.

VASCONCELOS, João Gualberto M. O coronelismo nas organizações: a gênese da gerência autoritária. In: DAVEL, Eduardo Paes Barreto; VASCONCELOS, João Gualberto M. (Orgs.). Recursos humanos e subjetividade. Petrópolis: Vozes, 1995.

WANDERLEY, Luís E. O que é universidade. São Paulo: Brasilense, 1999.

YIN, Robert K. Case study research: design and methods. EUA: Sage Publications, 1990. 